\title{
Pulmonary sclerosing hemangioma with lymph node metastases
}

\author{
NG Chan $M D^{1}$, DE Melega $M D^{1}$, RI Inculet $M D^{2}$, JG Shepherd MB BS ${ }^{1}$
}

NG Chan, DE Melega, RI Inculet, JG Shepherd. Pulmonary sclerosing hemangioma with lymph node metastases. Can Respir J 2003;10(7):391-392.

Pulmonary sclerosing hemangioma is an unusual benign tumour of uncertain histogenesis. In the past 50 years, hundreds of cases have been described. A case of sclerosing hemangioma with some unusual features, including a false-positive fine needle aspiration biopsy and histological evidence of lymph node metastases, is described.

Key Words: Biopsy; FNA; Hemangioma; Metastases; Pulmonary; Sclerosing

\section{CASE PRESENTATION}

A 19-year-old male construction worker presented with leftsided chest pain and a productive cough but no hemoptysis. He had a two pack-year smoking history but was otherwise healthy, with no family history of lung disease. Physical examination was unremarkable.

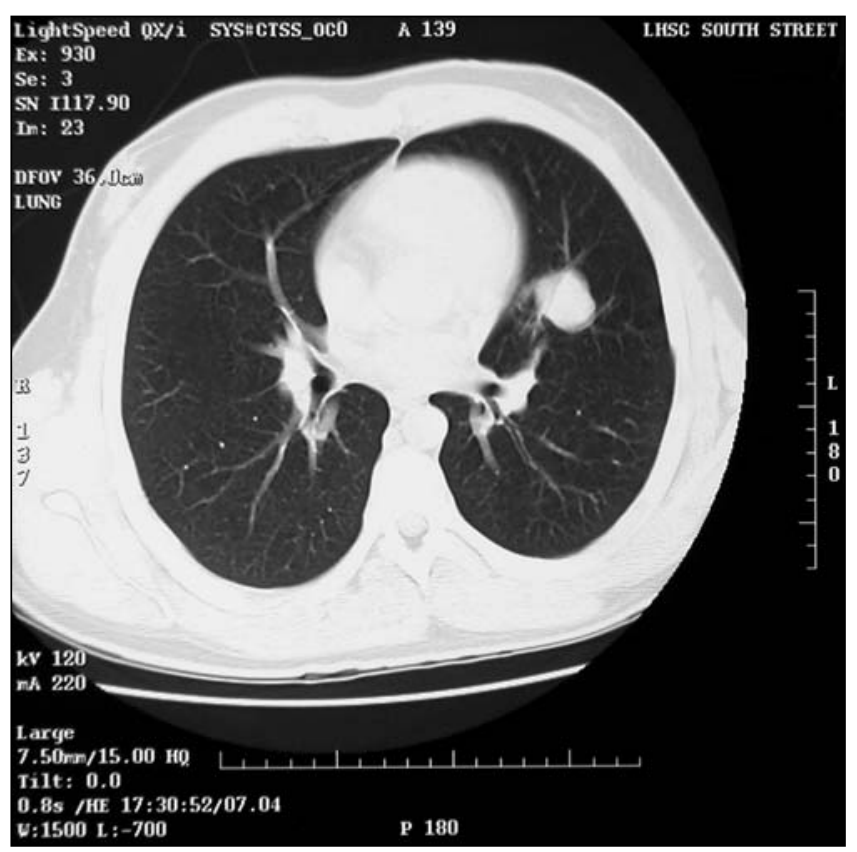

Figure 1) Computed tomography scan of the chest showing a mass in the lingula

\section{Un histiocytome pulmonaire accompagné de métastases des ganglions lymphatiques}

L'histiocytome pulmonaire est une tumeur bénigne inhabituelle dont l'histogénèse est incertaine. Depuis 50 ans, des centaines de cas ont été décrits. Est exposé un cas d'histiocytome accompagné de caractéristiques inhabituelles, y compris des résultats faux positifs d'une biopsie par aspiration à l'aiguille et des signes histologiques de métastases des ganglions lymphatiques.

Departments of ${ }^{1}$ Pathology and ${ }^{2}$ Thoracic Surgery, University of Western Ontario, London, Ontario

Correspondence and reprints: Dr JG Shepherd, Department of Pathology, London Health Sciences Centre, University Campus, 339 Windermere Road, London, Ontario N6A 5A5. Telephone 519-663-2930, e-mail jessica.shepherd@lhsc.on.ca 


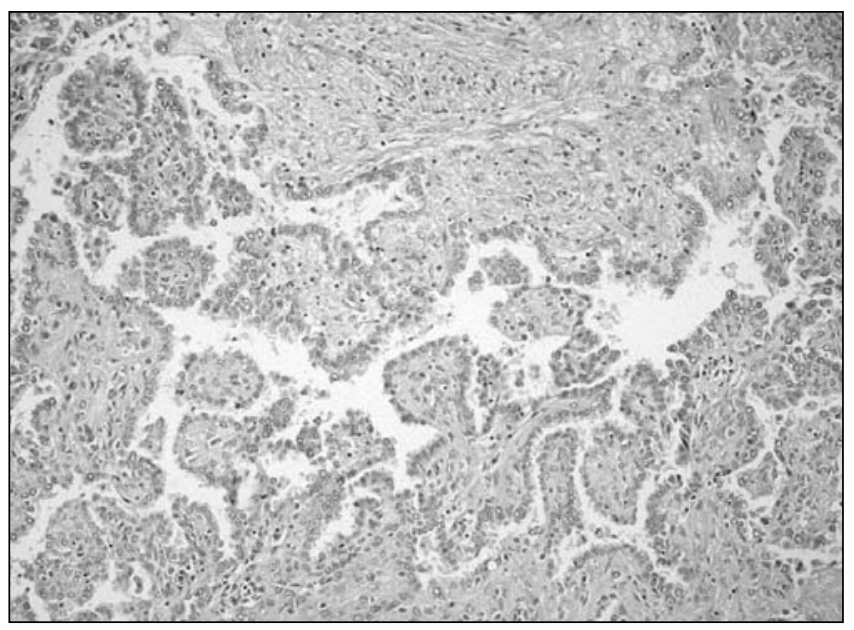

Figure 3) Region of tumour with papillary architectural pattern. (Hematoxylin and eosin stain, original magnification $\times 100$ )

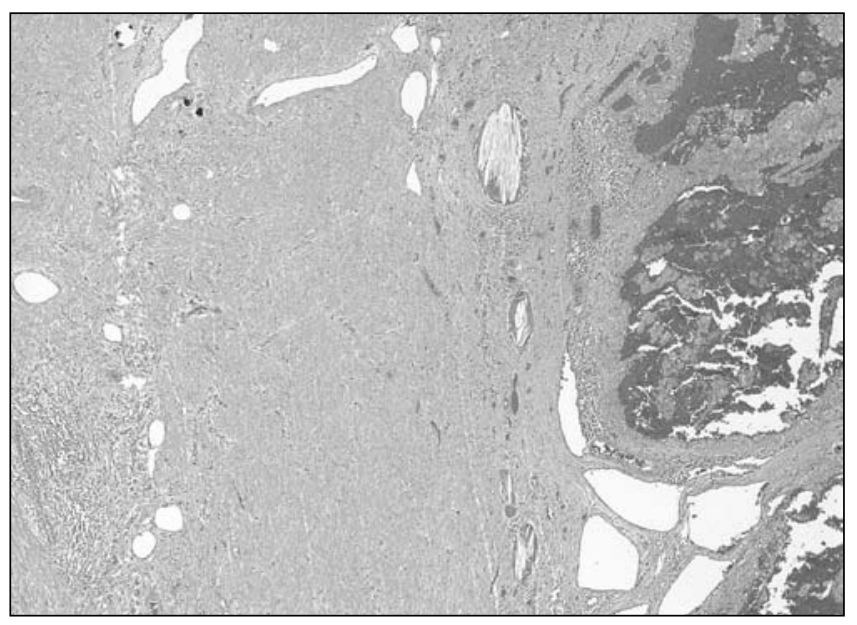

Figure 4) Sclerotic and hemorrhagic patterns of the tumour, with cholesterol clefts, calcified regions and areas of old blood. (Hematoxylin and eosin stain, original magnification $\times 40$ )

The patient underwent resection of the lingula. At frozen section, margins and two lymph nodes were negative for malignant cells. Histology on permanent sections showed four distinct patterns: solid, papillary (Figure 3), hemorrhagic and sclerotic (Figure 4). The tumour was composed of round to oval epithelioid cells with uniform, bland nuclei, as well as fine vesicular chromatin and small nucleoli. An intraparenchymal lymph node (Figure 5) and an interlobar lymph node were positive for metastases. Immunohistochemistry showed that the tumour was positive for cytokeratin (AE1/AE3 and CAM5.2), epithelial membrane antigen, vimentin, progesterone, placental alkaline phosphatase and thyroid transcription factor-1 (TTF-1). It was negative for S100 protein, carcinoembryonic antigen and CD34. This staining pattern showed a variegated tumour that expressed epithelial, mesenchymal and hormonal markers. The tumour was also positive for TTF-1, which

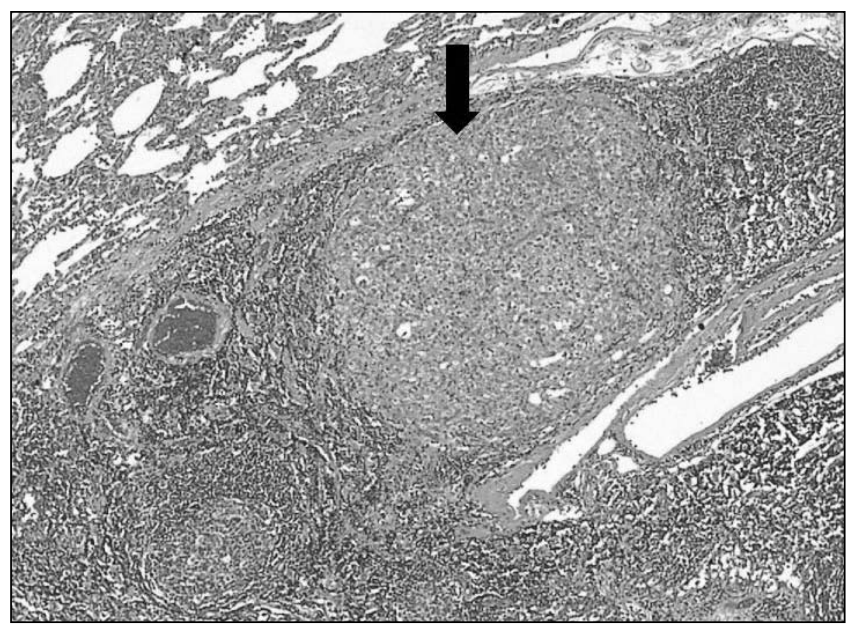

Figure 5) Intraparenchymal lymph node metastasis (arrow). (Hematoxylin and eosin stain, original magnification $\times 40$ )

demonstrated a pulmonary origin. The tumour histology and immunophenotype were diagnostic of sclerosing hemangioma (SH) with lymph node metastases. The patient received no additional therapy and remained disease-free one year later.

\section{DISCUSSION}

Pulmonary SH is an uncommon benign tumour first described by Liebow and Hubbel (1) in 1956. It is characterized by a mixture of solid, sclerotic, papillary and hemorrhagic histological patterns. Features of SH on Fine needle aspirate biopsy may mimic bronchioloalveolar carcinoma, carcinoid tumours and papillary neoplasms (2). The tumour cells typically express epithelial membrane antigen, cytokeratin, vimentin, estrogen and progesterone receptor proteins, and TTF-1, and are negative for S100 protein, carcinoembryonic antigen and endothelial cell markers (3).

Patients with SH may be asymptomatic or may present with chest pain and cough. Women are affected five times as frequently as men and the average age at diagnosis is 44 years. The tumour tends to be solitary, although multiple lesions are reported in less than $5 \%$ of cases. Surgery is considered curative and the overall prognosis is very good. Metastases are described in only $1 \%$ of cases but do not denote malignant behaviour clinically (4).

\section{REFERENCES}

1. Liebow AA, Hubbel DS. Sclerosing hemangioma (histocytoma) of the lung. Cancer 1956;9:53-75.

2. Gal AA, Nassar VH, Miller JI. Cytopathologic diagnosis of pulmonary sclerosing hemangioma. Diagn Cytopathol 2001;26:163-6.

3. Devouassoux-Shisheboran M, Hayashi T, Linnoila RI, Koss MN,

Travis WD. A clinicopathologic study of 100 cases of pulmonary sclerosing hemangioma with immunohistochemical studies. TTF-1 is expressed in both round and surface cells, suggesting an origin from primitive respiratory epithelium. Am J Surg Pathol 2000;24:906-16.

4. Yano M, Yamakawa Y, Kiriyama M, Masaki H, Murase T.

Sclerosing hemangioma with metastases to multiple nodal stations. Ann Thorac Surg 2002;73:983-5. 


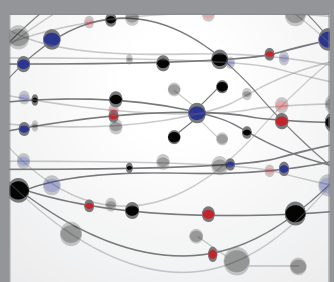

The Scientific World Journal
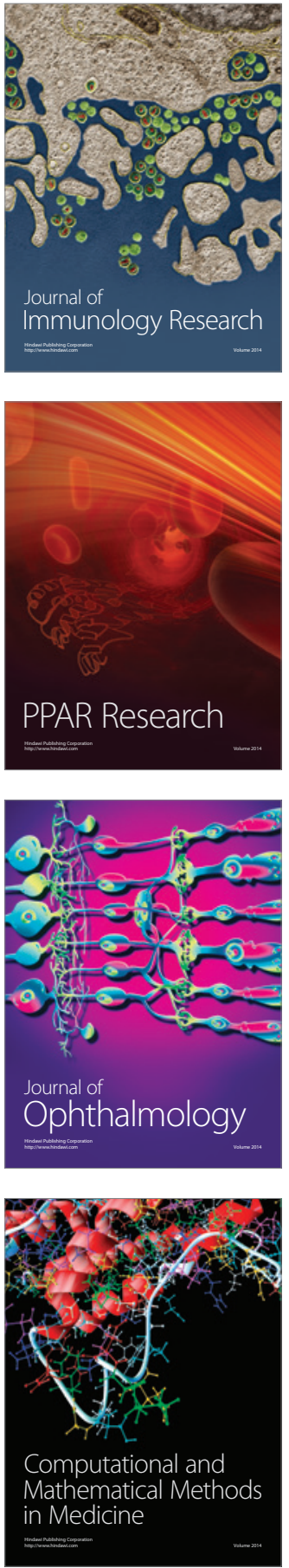

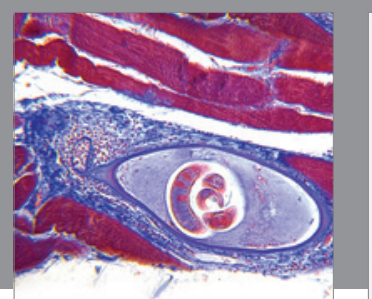

Gastroenterology Research and Practice

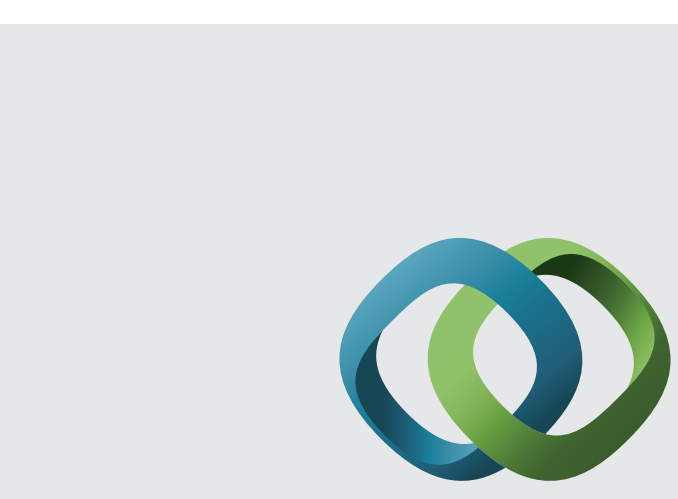

\section{Hindawi}

Submit your manuscripts at

http://www.hindawi.com
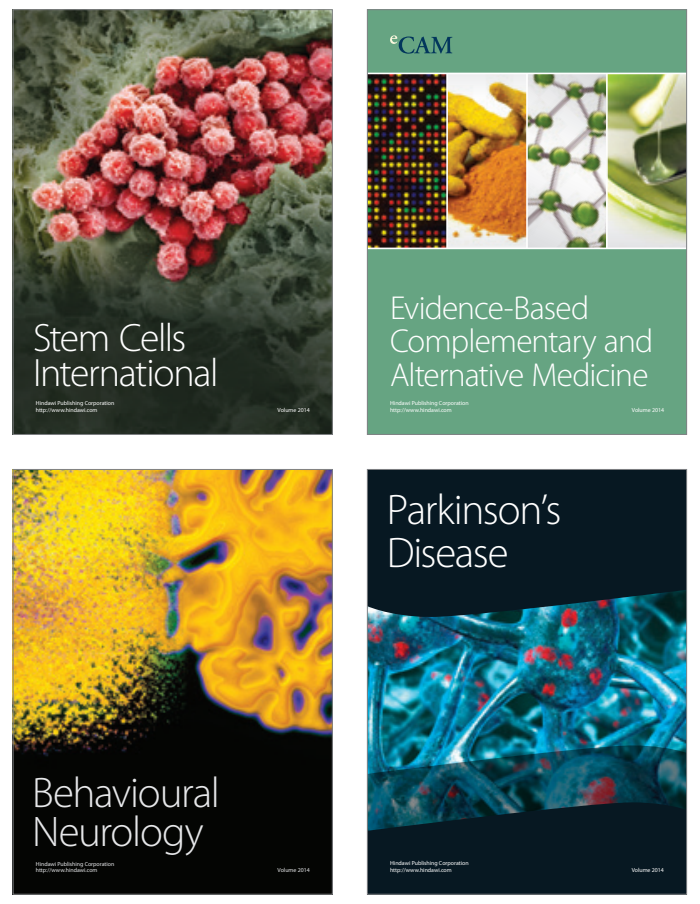
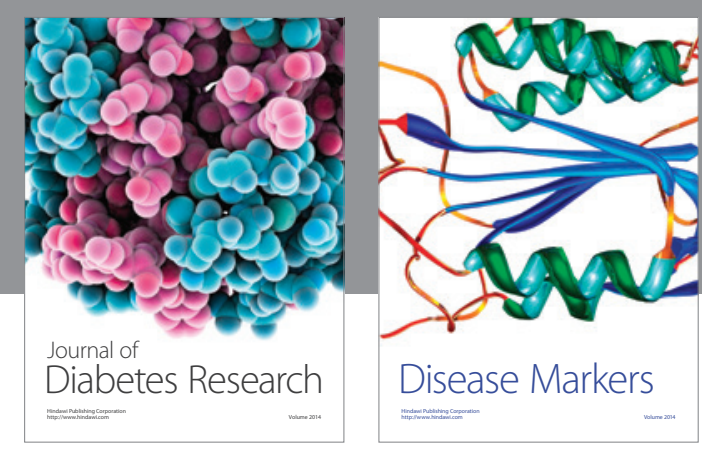

Disease Markers
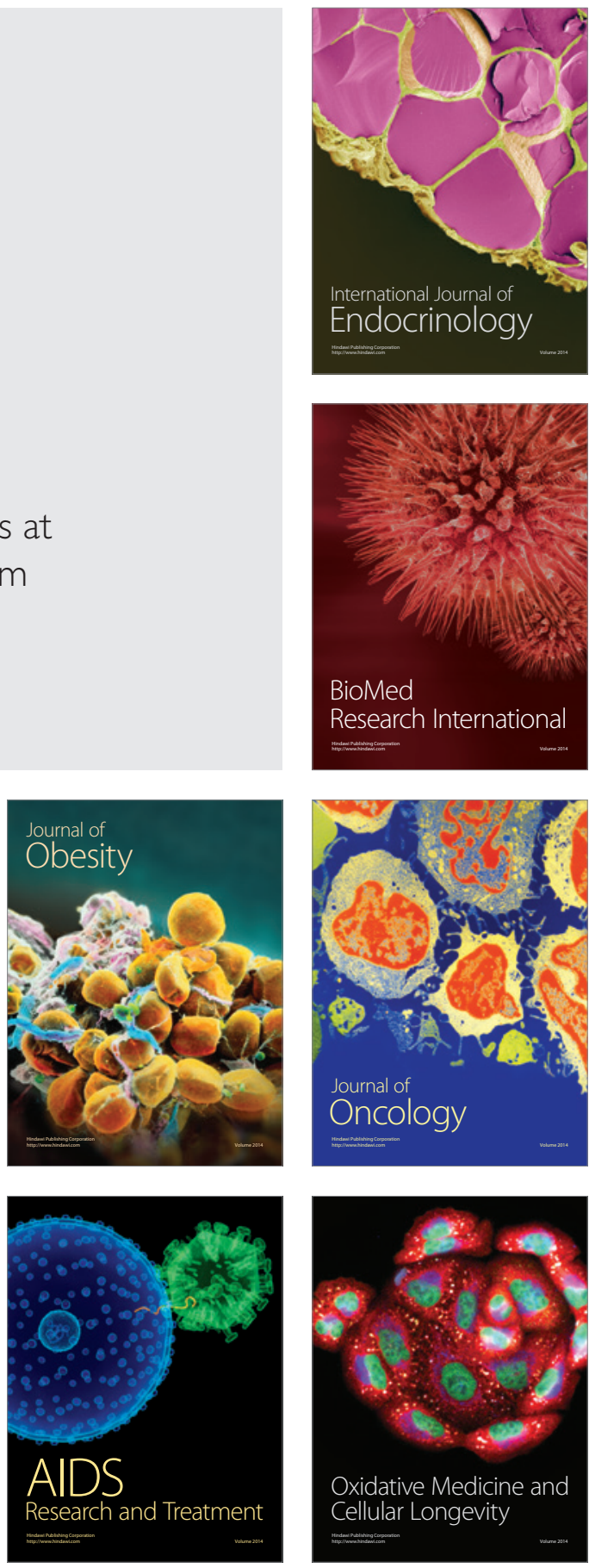